This item was submitted to Loughborough's Research Repository by the author.

Items in Figshare are protected by copyright, with all rights reserved, unless otherwise indicated.

\title{
Evolution in ecodesign and sustainable design methodologies
}

PLEASE CITE THE PUBLISHED VERSION

https://doi.org/10.1007/978-981-4451-48-2_6

PUBLISHER

(C) Springer

VERSION

AM (Accepted Manuscript)

LICENCE

CC BY-NC-ND 4.0

REPOSITORY RECORD

Sheldrick, Leila, and Shahin Rahimifard. 2019. "Evolution in Ecodesign and Sustainable Design Methodologies". figshare. https://hdl.handle.net/2134/14094. 
This item was submitted to Loughborough's Institutional Repository (https://dspace.lboro.ac.uk/) by the author and is made available under the following Creative Commons Licence conditions.

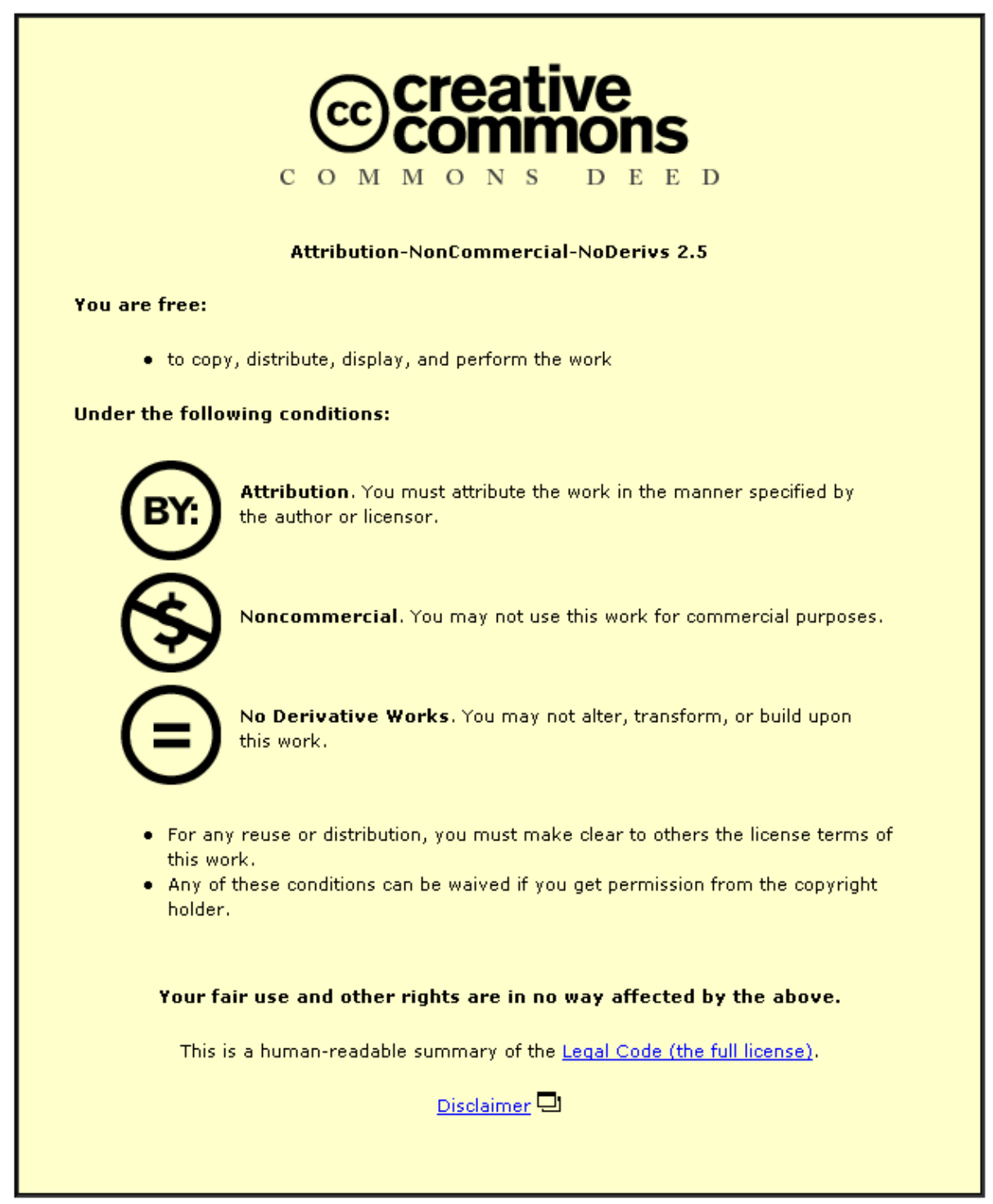

For the full text of this licence, please go to: http://creativecommons.org/licenses/by-nc-nd/2.5/ 


\title{
Evolution in Ecodesign and Sustainable Design Methodologies
}

\author{
L. Sheldrick ${ }^{1}$, S. Rahimifard ${ }^{1}$ \\ ${ }^{1}$ Centre for Sustainable Manufacturing and Recycling Technologies (SMART), \\ Loughborough University, UK
}

\begin{abstract}
The majority of the environmental impact of a product is decided during the design phase, and as such there has been a rapid growth in generation of methodologies and tools that aim to improve design and include sustainability considerations in product development. Although these methodologies and tools have introduced measurable benefits, in most cases they have been incremental in nature as opposed to producing radical 'Factor $X$ ' improvements. This highlights the need for a careful analysis of existing sustainable design methods to identify their shortcomings and to enable a greater understanding of how to unlock the full potential of design improvements. This paper provides a brief overview of the evolution of ecodesign and its extension into sustainable design. It assesses the key influencing factors of current practice and identifies a number of future research challenges, promoting the next stage in its development in which sustainability will become a ubiquitous part of the design process.
\end{abstract}

\section{Keywords:}

Sustainable Design; Design for Sustainable Behaviour; Ubiquitous Sustainability

\section{INTRODUCTION}

Sustainable design is no longer a new concept. It has been shown that a significant proportion of the environmental impact of a product is decided during the design phase [1] and therefore, systematic methodologies and tools for formally embedding environmental concerns into product design have been in development for almost three decades.

One of the earliest examples, Design for Environment (DfE), is now more commonly referred to as 'Ecodesign' and has expanded to be the term given to any design strategies that focus on improving the ecological aspects of a product. Sustainable Design (SD), also known as 'Design for Sustainability' (DfS), builds on ecodesign concepts by additionally taking into account economic and social considerations and aiming to generate solutions that consider the whole life cycle of the product.

SD methods prompt designers and engineers to consider key factors for sustainability, and enable them to modify their designs based on a number of predefined objectives. In most applications, the current methods only generate slightly modified or improved designs and are often applied late in the design process; after many key decisions have been made and when too many constraints are in place. They can also be difficult to implement and to fit within the larger context of product development, requiring a great deal of knowledge to negotiate and offering guidance based on conflicting considerations. Although these SD methods offer a broad set of tools for addressing environmental considerations, they do not yet place the same emphasis on social and economic considerations.

Within Industry there has been a widespread focus on implementing changes to production activities as a first step towards improving environmental performance of manufacturing companies. In this context, many companies have not utilised design as a part of their sustainability effort and do not consider design processes as a strategic approach to organisational improvements. A recent report by the European Commission (EC) highlights that, while the situation is improving, around a third of companies still fail to utilise the full potential of design during product development [2].
With simple products, and in smaller companies, design processes are more agile and implementing change is more feasible. However, in the case of complex products and larger companies, implementing new design practices can provide greater challenges; particularly in applications where the product is developed using a distributed design approach. Such challenges significantly limit the potential impact of sustainable design activities in high volume, high impact sectors which offer the greatest potential for environmental and economic gains.

Therefore, the authors argue that current SD practice is unable to deliver to its full potential. They also highlight a need for better understanding of the shortcomings associated with SD methods and tools in order to be able to integrate sustainability considerations into the initial stages of product development, as opposed to a series of 'afterthought' design improvements.

This paper aims to provide an overview of the evolution of SD, and of the future challenges it will face. The first section of this paper presents a brief overview of the field of SD. The second section critically analyses three key areas of current SD practice and their effect on product development. The final section presents a number of future research challenges for SD. It proposes the next steps towards embedding sustainability into the design process, identifies new opportunities for inclusion of social considerations, and discusses the extension of SD within and beyond product development.

\section{BRIEF OVERVIEW OF SUSTAINABLE DESIGN}

The first widespread design methods which specifically considered the environment began to emerge during the 1980s and 1990s with the appearance of a number of different 'Design for $X$ ' (DfX) methodologies. As awareness of environmental issues grew over the following years, governments enforced a variety of environmental legislations which became the main drivers towards widespread implementation of SD practices. A simplified timeline for a variety of drivers, tools and legislation influencing the evolution of ecodesign and SD practices is shown in Figure 1. 


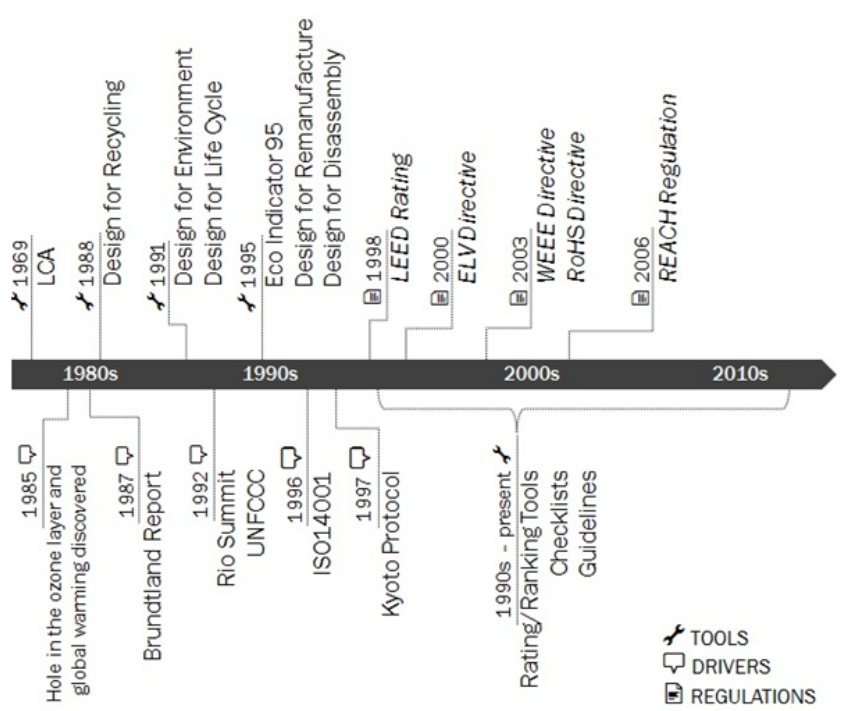

Figure 1: Key milestones and drivers of sustainable design.

These forerunning DfX methodologies were developed using principles first laid out by Boothroyd and Dewhurst in their Design for Assembly framework (DfA) [3]. This approach enabled systematic incorporation of rising environmental concerns into design activity. As governments and regulatory bodies became more aware of the scale of environmental problems, they began to develop legislations to regulate industry and mitigate impacts. This regulatory influence has resulted in a second wave of generation of environmental design methodologies that are more focused and directed to meet the specific targets of these legislations.

However, in recent years the demand for better design solutions has become even more urgent as customer demand, resource scarcity, and energy costs continue to rise. As such, the expectation from SD methods to deliver radical 'Factor $X$ ' improvement is gaining momentum, as highlighted in a recent study by Rio et al. [4], in which they observe a significant growth in the number of publications on ecodesign methods in the last five years. Despite this growth in research activities, there has been little evidence showing widespread industrial uptake of proposed SD methodologies and tools [5][6][7].

In the cases where environmental design activities have been employed, the main drivers for uptake were found to be either pressure from customer demand, or from imposed regulations and legislation [5][6]. It was observed that the most successful examples of implementation occurred when driven by more conventional business concerns, such as money saving or increased sales from improved customer perception [6][7].

In the cases where environmental design activities were not yet employed and no legislation was in place, it was found that businesses were often unaware of the environmental impacts associated with their products [6] and the significant economic gains that can be achieved through adopting SD methods.

Figure 2 by Lewis et al. [8] highlights the cumulative 'lock-in' of the environmental impact of a product over the course of its lifecycle, illustrating that the chances for environmental improvement decrease as a concept is developed, decisions are made and product knowledge increases. This publication, in addition to a number of others, has clearly emphasised that the early stage of the design phase has the greatest influence over the environmental impact of a product. In some cases it was shown that, approximately $80 \%$ of the total impact is decided after only $20 \%$ of the design activity has been undertaken [1].
The later stages of detail design are the point at which many existing SD methods and tools are typically employed, however, at this stage they provide limited potential to significantly decrease the environmental impacts of the product. Although their overall contribution is minimal, many of these tools directly address the immediate environmental considerations of detail design, such as low impact material choice. As such, a great deal of work has also been done to develop design tools that specifically address challenges with the subsequent lifecycle phases, to try to mitigate the impacts of the product throughout the rest of its life.

Design for Manufacture has been a particular area of focus with the creation of methods such as DfA offering design improvements that are simple to measure and predict, often yielding obvious economic gains in the form of material, energy or production efficiency. Design for disposal or recovery has also seen a large amount of work driven by legislations enforcing end-of-life (EOL) targets for products. This has resulted in generation of a range of methods focussing on specific EOL strategies, for example design for disassembly, remanufacture, reuse or recycling.

The 'use' phase however has seen very little work comparatively, and research in this area is still relatively new despite the fact that the 'use' phase of certain types of products has been found to be particularly environmentally significant. For example, it was found that $90 \%$ of life cycle energy consumption of household appliances takes place in the use phase, and of this consumption, up to $90 \%$ is determined during design [9]. Research into design for sustainable 'use' has a variety of names including 'Design for Sustainable Behaviour' (DfSB) and 'Design with Intent'. These studies cross the borders between social sciences and design and consider how to include and influence consumer behaviour as part of the early conceptual stages of design activity. The findings however have yet to be integrated into the wider product development process and current studies simply explore the key considerations, offering suggestions and best practices.

The current level of research interest in SD on one hand identifies the potential benefits of wide scale industrial adoption and utilisation, and on the other hand, highlights significant research gaps that require further investigation, such as embedding sustainability consideration into product development from the earliest stages, developing more simple and appropriate tools, or creating methodologies which include environmental, economic and social issues holistically. Existing research also highlights a need to investigate the organisational and social factors of implementing SD as it has been observed that in many cases, the largest barriers to successful uptake were social-psychological issues such as lacking communication or cooperation between actors, organisational complexities, and disparities in language and context [5].

The remaining sections of this paper analyse a number of these research areas in more detail in order to better understand the key factors which have shaped current SD practice.

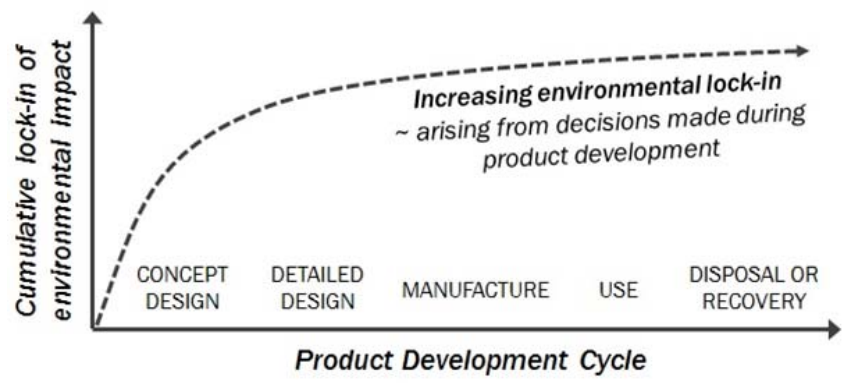

Figure 2: Conceptual representation of environmental lock-in over a product's lifecycle. Adapted from [8]. 


\section{CURRENT EVOLUTION OF SUSTAINABLE DESIGN}

\subsection{The Driving Factors for Sustainable Design}

A broad uptake of SD practices has been encouraged by a rising awareness of environmental issues amongst consumers, the legal requirements of new regulations and the scarcity of materials and other resources, however, many companies have failed to appreciate the full potential of implementing SD activities. In order to maximise the impact of future initiatives, it is important to look at the underlying drivers for uptake that are currently shaping SD.

One of the key influential factors in uptake of SD practices has been the introduction of various industry standards, ecolabels and product certifications. These are all voluntary schemes which enable companies to measure themselves against specific predefined targets and are often used to help market products and clearly communicate that a certain environmental standard is being maintained. This offers a simple way to show customers that the product, and by extension the company, are environmentally conscious.

Industry standards typically provide general supportive information for companies who wish to improve design practice in a certain area. For example, ISO/TR 14062:2002 details the process of integrating environmental aspects into product design and development [10]. Ecolabelling and product certification are similar in nature, however, the information given is more specific and products are required to conform to clearly defined criteria in order to achieve certification, or be awarded an ecolabel. For example, the EPEAT (Electronic Products Environmental Assessment Tool) register is an environmental rating system which uses a number of criteria based on ANSI standards to give gold, silver or bronze status to different products based on a number of characteristics covering their full lifecycle [11].

Additional factors significantly influencing the advancement of SD are environmental regulations and legislations which set specific, compulsory requirements companies must comply with by law. In this context, the most influential recent legislations are those related to 'Extended Producer Responsibility' (EPR). For example, the Waste electrical and electronic equipment (WEEE) directive, and the End-of-life vehicles (ELV) directive. Both of these EU directives require manufacturers to take responsibility for their EOL products, arranging for their collection from the consumer and meeting prescribed recycling targets. In addition to recovery and recycling targets, the EPR legislations aim to encourage environmental consideration related to EOL processing of the products during the design stage. Another example regulation is the Eco-design Directive for Energy-using Products (EuP directive). In this case, guidelines are less prescriptive and instead of quantitative targets, a framework is provided to help manufacturers adopt changes during their design process that will help reduce the energy consumption and other negative environmental impacts of the final products.

These various schemes and legislations undoubtedly offer simple ways for companies to reduce the environmental impacts of their products, however, their effect on the design process is often minimal as the solutions implemented are frequently 'end-of-pipe' and only address the minimum requirements by means of incremental and targeted improvements as afterthoughts [12].

In addition, the targets set by these various schemes can also create confusing trade-off situations. An example of this can be seen in the case of the ELV directive which sets recycling targets based on the weight of a vehicle. Recent LCA studies have highlighted that one of the most influential environmental impacts associated to the lifecycle of a vehicle is the fuel consumption during the use phase, which is largely determined by the weight of the vehicle. This would imply that an automotive manufacturer should try to use lightweight materials, however, these may affect the ability to achieve recovery and recycling targets set by the directive. For example, replacing steel with plastic or composite will have many possible knock on effects such as reducing the quality of waste streams at EOL, and increasing difficulties in separation and recycling of these waste streams.

This illustrates that while these schemes encourage uptake, they may also limit potential for radical improvement and lock companies in to suboptimal solutions [12]. They set targets which can be systematised and do not necessarily require creativity or aid understanding of SD issues by offering prescriptive guidelines and simply requiring compliance.

\subsection{Ecodesign Tools for Product Development}

There are a wide range of different tools available for the implementation of ecodesign. Although a small number of these take economic factors into account, very few incorporate the social considerations required for true sustainable design and as such, these tools can only be considered as 'ecodesign' tools.

Ecodesign tools utilise a range of approaches that can be broadly categorised [13] as shown in Figure 3. These tools can each be used in isolation, however, many can also be used concurrently with others as each method has a differing scope, a differing stage for application, and a differing environmental focus. For example, Design for Recycling (DfR) provides general guidelines for best practices, is usually applied during the detail design phase and focuses on end of life. In contrast, the MET (Material Energy and Toxicity) matrix provides a framework for structured analysis against guiding criteria and can be used from the initial design stages onwards, to consider the entire life cycle of the product.

A great deal of research exists which offers examples of theoretical or practical applications of ecodesign tools as well as example case study products [4]. In addition, there have been a large number of studies that compare and assess various ecodesign tools against different criteria [4][6], however, little work has been done to evaluate and assess the performance and usefulness of these tools when used in an industrial environment [14]. From the studies available however, a number of conclusions can be drawn about the applicable scope of existing tools and methodologies, as well as their perceived strengths, weaknesses, and potential effectiveness.

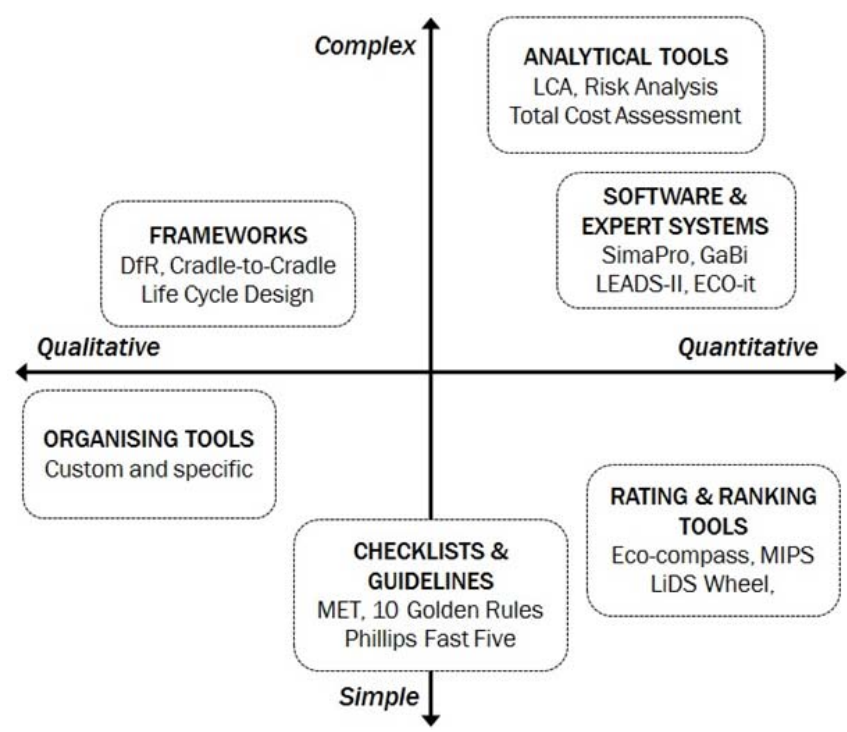

Figure 3: Classification of Ecodesign tools - Difficulty vs. Input type. 
It is generally observed that utilising ecodesign tools requires significant of knowledge, demands a lot of data screening, and can become very time consuming [15]. They also present many conflicting considerations and trade-offs with little guidance on decision making, and in the majority of cases they have to be customised prior to implementation to meet the specific needs of a particular company type or product sector [4][7]. Although this adds an extra layer of complication, studies have shown that these specific, customised tools are more successful and more readily taken up by industry [5]. As such, many companies who wish to formalise the consideration of ecodesign within their development process will create their own tools to address their critical issues specifically, and to fit within existing frameworks and procedures.

The use of an ecodesign tool in the early stages of product development is discussed in a recent study of fuel cell design [16]. In this example, LCA software was used to assess early concepts and inform strategic decision making. Data gathered was used to select the most appropriate concepts and materials for the final products based on potential EOL scenarios. In this case the fuel cells were a completely new product for the manufacturer, however, the study required a great deal of prior knowledge to conduct. Even in the early stages it was important to understand both the potential future legislative requirements, and the full composition of at least two initial concepts. This illustrates that although ecodesign tools can be employed in the development of completely new concepts, a large amount of knowledge is required which means a large number of decisions must have already been made before the environmental considerations are taken into account.

Overall, it can be observed that many ecodesign tools currently only offer incremental improvements through preventative measures. This is because they are frequently simply added onto the design process as an afterthought and require a great deal of prior knowledge of the products. In addition, many studies found the tools were difficult to understand and difficult to manage and fit within existing product development processes. These difficulties have dictated the level of uptake and level of effectiveness of the tools and highlighted areas for future improvement.

\subsection{The Impact of Product Types and Business Models on SD}

Organisational complexities have been found to be a consistent challenge in implementing SD activities [5]. These offer a particularly tough problem as different types of products require very different organisational approaches to the design process, and the structure of the design process will change not only based on the sector and size of a business, but also on the complexity, volume, shelf-life, service-life, and other key characteristics of the products themselves. These different approaches will have a large effect on where and when SD activities will take place. The larger, more complicated and more structured a company and its product development process become, the more difficult it is to make changes during design as 'lock-in' decisions become more firm and more frequent during the development process.

A distributed design approach is usually undertaken in the case of very complex products such as cars which require several subassemblies and components, which themselves consist of many parts. The complex design chain in these companies often involves a number of suppliers with their own embedded levels of complexity. For example, a car manufacturer might purchase their headlamp units from a supplier who in turn purchases the light bulbs from a third company who may simply act as a distributer, and are not involved in the design or production of the light bulbs. An example of this ' $V$ ' shaped model against a more simple design model is shown in Figure 4.

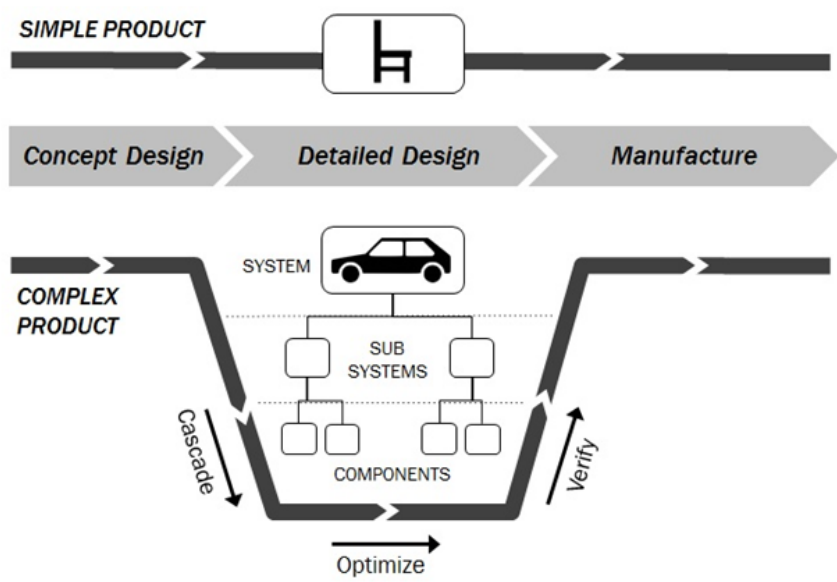

Figure 4: Characterisation of the product development process for a simple and complex product. Adapted from [1].

This highlights the complications in communication throughout a ' $\mathrm{V}$ ' shaped model where product development often involves the work of a number of different design teams, both within the parent company itself and at associated suppliers and subcontractors. In addition, products developed in ' $\mathrm{V}$ ' shaped models often tend to have a larger environmental impact than more simple products as they usually have a longer service life and are available to purchase without upgrades to the design, for a larger number of years.

Due to this, examples of the inclusion of environmental considerations in distributed design models are not uncommon; particularly in vehicle design as the products are governed by the ELV directive. Implementing and controlling environmental considerations at the various levels within a complex design chain can however, present a great number of challenges with communication at each stage, and with collecting, storing and sharing knowledge between all parties. Due to these difficulties, it has been seen that car manufacturers are focussing on 'end-ofpipe' solutions such as recycling and shredder separation [12] as opposed to addressing challenges at the design phase and trying to embed eco considerations throughout the design chain.

The above mentioned organisation structures and product complexities have also had an impact on implementation models for adopting SD practice. Considering who conducts SD activities decides where and when the environment will be considered during the design process and it has been noted that there are three main variations as to how ecodesign can be included in design [4]:

1. Externalised (with a consulting agency).

2. Treated as a distinct department in the company.

3. Integrated into expert activities (such as engineers).

Each situation offers different benefits and drawbacks with respect to agility, information sharing and level of confidence in expertise, however, further investigation is required to identify how each of these scenarios affects the integration of SD from the outset of design activity.

These examples discussed highlight the importance of company structure and the effect it has on SD. In distributed design models, there are large challenges in organisation and communication, as well as in visibility and control over what happens throughout the whole design chain. This, combined with uncertainty over the best methods for implementing SD, can limit uptake and has dictated the extent to which organisations are able to incorporate sustainability in their design activities. 


\section{FUTURE CHALLENGES AND OPPORTUNITIES FOR SD}

In order to maximise the potential for adoption of SD practices, there are a number of areas in need of further investigation, including:

1. The improvement of the design process so that SD is not an afterthought, but is incorporated centrally throughout the design process from its outset.

2. The improvement of SD implementation methods within a company's product development process, particularly in the case of complex organisations and products.

3. The improvement and inclusion of social considerations which are largely underrepresented in current SD practices.

4. The linking of SD practices with other relevant activities within a manufacturing company, such as process and plant design.

\subsection{Embedding SD at the Core of the Design Process}

Throughout this study it was found that SD activity was frequently applied as an afterthought. This has reduced its effectiveness and prevented it from fulfilling its full potential to make considerable, as opposed to incremental changes. Future SD methods need to offer transformational improvements, to include sustainability consideration from the very beginning of the concept design phase.

To do this, in the first instance, there is a need to create a purposeful overlap between sustainability considerations and the various stages of design. In the long term however, the ultimate goal should be to replace the existing approach of 'design followed by ecodesign', with one holistic, integrated, inherently sustainable design process as shown in Figure 5.

\subsection{Improving SD Implementation Models}

As discussed, complex business models raise a variety of challenges with integrating and implementing SD throughout the whole design chain. There is a large challenge in developing more clearly defined roles and processes for the actors within chain. This highlights a need to better understand the issues with ' $V$ ' shaped models and how, and where to integrate SD expertise within different organisational structures

In addition, current SD tools and methodologies do not yet encompass all the relevant considerations required to fully address the issues at hand. More actionable, holistic tools are needed which on one hand are simple so that they can be used from the outset of design, and on the other hand can be linked and integrated with other fundamental methods and systems used within the product development process, for example CAD, CAE, FEA, House of Quality.

\section{NOW: Ecodesign as an afterthought}

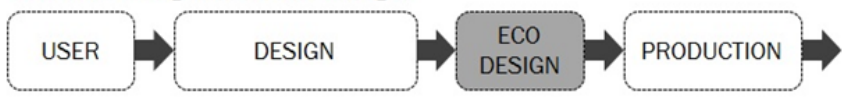

NEXT: Extended scope of sustainable design

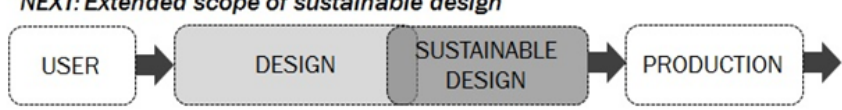

FUTURE: Ubiquitous sustainability

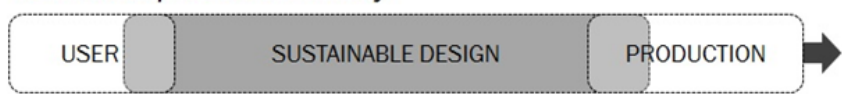

Figure 5: Proposed evolution of the sustainable design process.
In addition to these, a number of other critical success factors for further developing SD and integrating it into product development can be identified as follows:

- Collaboration: This needs to be facilitated and encouraged at every level of company activity - across different departments, disciplines, companies, and even sectors.

- Communication: Facilitating an open dialogue and establishing a common language will be needed to cross the barriers created by company structures, different disciplines, and different cultures.

- Improved Metrics: It is very difficult to measure the success and outputs of design activity. There is a need to not only better understand the value of design, but also have a means by which to more clearly measure progress and establish common ground with the surrounding activities.

- Knowledge: Access to appropriate knowledge when and where it is required will be key to facilitating successful implementation of SD activities. Knowledge needs to be properly created, stored, and shared so that it can be readily available to those that need it, and presented in a way that is easily understood.

\subsection{Inclusion of Social Factors in SD}

It has been well established that social factors are critical to the success, or failure of implementation of SD in product development. In the future, social factors will need to extend beyond company borders in order to realise the full potential of SD.

In this context, the concerning impact of the 'use' phase has highlighted a great potential for improvement of SD practices. This is to be achieved by exploring the application and integration of DfSB further and attempting to directly influence consumer behaviour towards a more sustainable consumption pattern through a series of design features and considerations.

In addition, many organisations are beginning to discuss and explore more collaborative design models which have the ability to address more specific user needs. In relation to this, a recent European design report stated that: "the conventional borders between product design, production and the user are beginning to merge. The internet and the active use of social media not only enable the dissemination of digital works, but also the co-creation of products or services that can engage users from the outset." [2]

Traditional product development is an interdisciplinary task involving many different actors, from designers to mechanical engineers, production technicians and quality officers. Co-creation and participatory design aim to extend this to involve all stakeholders in the process from the outset. Collaboration has long been credited as being a key component of innovation, and the recent socio-technological advances discussed above are creating an environment enabled by ubiquitous computing (ubicomp) that is more conducive to change and to encouraging participation.

In much the same way as these advances have seen sweeping cultural changes in communication, politics and news, similar tools can be used in the future to change consumption behaviours and gather information from more engaged customers. This has the potential to involve all stakeholders and move design activity from interdisciplinary to transdisciplinary practice, as well as to build better relationships for improved stakeholder engagement and embedded sustainable behaviours. 


\subsection{Integration of Sustainable Product, Process and Plant Design}

This paper has so far focused on the product design process, however, there are new and unprecedented scenarios developing which offer unique challenges and opportunities for expanding the scope of sustainable design beyond product development.

A key example of this is the increasing rate of change of manufacturing requirements. In recent years it has become evident that more frequent changes to product designs, rapid progress in manufacturing technologies and ever changing customer demands are highlighting a need to rethink current practice. It is widely recognised that in order to respond to these factors, there is a need for a more flexible, responsive and agile design process which not only considers the products, but also the process and production systems that are used to manufacture them.

In addition to these factors, a set of new challenges in this area are appearing as unprecedented opportunities arise in developing countries. These emerging markets are growing rapidly and offer completely new and different priorities in customer demand, levels of technology, costs of labour, and even local skill levels. The considerations for companies entering these markets will be very different when deciding how to manufacture items and design new plants and supply chains. This offers a vast opportunity to implement change from the outset of designing the whole system and approaching the task from the start with an integrated 'holistic engineering design' approach which considers product, process and plant design together

\section{CONCLUSIONS}

The power of design to influence behaviours and transform industries has led to widespread recognition that design will play a key role in helping to achieve more sustainable production and consumption whilst securing and developing economies.

As such, the need for sustainable design is an argument that has been well made and recent developments in ecodesign and SD methods and tools have created significant impact, however, the demands from sustainability are rising. As we become more aware of the scale of the environmental challenges we are facing, the effects of resource shortages, climate change, and energy futures are becoming more prominent. This requires a reassessment of our progress. We need to better understand what has been achieved through current SD approaches, and where we need to be in the future. We can then target research to extend the scope and potential of SD activities.

This study has made a clear case for the need to improve the potential impact of future SD practices and has outlined four key challenges for more effective embedding of sustainability into product development. The next stage of this research will focus on further investigation to develop methodologies and tools to meet the specific requirements and demands of these four areas of opportunity identified for SD.

The ultimate goal of this research is to facilitate a move to a situation where sustainability is inherent and ubiquitous within the product development process - i.e. to move from Design for Sustainability into 'Ubiquitous Sustainability'. For this, we need better informed designers, better informed engineers, better informed managers, and better informed customers. We need to raise awareness of sustainability issues amongst all involved, requiring better education and a shift in both social and industrial expectations and practices.

\section{REFERENCES}

[1] Otto, K.N., Wood, K.L. (2001); Product Design - Techniques in Reverse Engineering and New Product Development, Prentice Hall, New Jersey, USA.

[2] European Commission. (2012); Design for Growth \& Prosperity: Report and Recommendations of the European Design Leadership Board, European Design Innovation Initiative, Helsinki, Finland.

[3] Kuo, T-C., Huang, S.H., Zhang, H.C. (2001); Design for manufacture and design for ' $X$ ': concepts, applications, and perspectives, in: Computers \& Industrial Engineering, Vol. 41, pp. 241-260.

[4] Rio, M., Reyes, T., Roucoules, L. (2013); Toward proactive (eco)design process: modelling information transformations among designers activities, in: Journal of Cleaner Production, Vol. 39, pp. 105-116.

[5] Boks, C. (2006); The soft side of ecodesign, in: Journal of Cleaner Production, Vol. 14, pp. 1346-1356.

[6] Deutz, P., McGuire, M., Neighbour, G. (2013); Eco-design practice in the context of a structured design process: an interdisciplinary empirical study of UK manufacturers, in: Journal of Cleaner Production, Vol. 39, pp.117-128.

[7] Knight, P., Jenkins, J., Adopting and applying eco-design techniques: a practitioners perspective, in: Journal of Cleaner Production, Vol. 17, pp. 549-558.

[8] Lewis, H., Gertsakis, J., Grant, T., Morelli, N., Sweatman, A. (2001); Design + Environment: A Global Guide to Designing Greener Goods, Greenleaf Publishing, Sheffield, UK.

[9] Tischner, U. (2001); Tools for ecodesign and sustainable product design, in: Charter, M., Tischner, U. (Eds.), Sustainable Solutions: Developing Products and Services for the Future, Greenleaf Publishing, Sheffield,UK, pp. 263-280.

[10] ISO/TR 14062:2002; Environmental management Integrating environmental aspects into product design and development, International Organization for Standardization, Geneva, Switzerland.

[11] EPEAT. (2010); Environmental Benefits of 2010 EPEAT Purchasing, Green Electronics Council, Portland, USA.

[12] Gerrard, J., Kandlikar, M. (2007); Is European end-of-life legislation living up to expectations? Assessing the impact of the ELV Directive on 'green' innovation and vehicle recovery, in: Journal of Cleaner Production, Vol. 15, pp. 17-27.

[13] Baumann, H., Boons, F., Bragd, A. (2002); Mapping the green product development field: engineering, policy and business perspectives, in: Journal of Cleaner Production, Vol. 10, pp. 409-425.

[14] Chen, C., Zhu, J., Yu, J-Y., Noori, H. (2012); A new methodology for evaluating sustainable product design performance with two-stage network data envelopment analysis, in: European Journal of Operational Research, Vol. 221, pp. 348-359.

[15] Lofthouse, V. (2006); Ecodesign tools for designers: defining the requirements, in: Journal of Cleaner Production, Vol. 14, pp. 1386-1395.

[16] Wright, E.I., Rahimifard, S. (2012); Strategic decision making for end-of-life management of fuel cells, in: Proceedings of the 19th CIRP International Conference on Life Cycle Engineering (LCE2012), pp.185-190, Berkeley, USA. 